RESEARCH

\title{
THE EFFECTS OF RENAL INSUFFICIENCY AND AGE ON MORTALITY IN GERIATRIC PATIENTS WITH NON-ST-SEGMENT ELEVATION MYOCARDIAL INFARCTION
}

Turkish Journal of Geriatrics

DOI: 10.31086/tigeri.2021.228

2021; 24(3): 303-314

- Pınar DEMIR GÜNDOĞMUŞ 1 . .

- Emrah AKSAKAL ${ }^{2}$.

- Oğuzhan BIRDAL ${ }^{3}$

- Ibrahim Halil TANBOĞA4

CORRESPONDANCE

1 Pınar DEMIR GÜNDOĞMUŞ

Kirkkkale Yüksek ihtisas Hospital, Cardiology,

Kirkkale, Turkey

Phone: +903182151425

e-mail: 1pinar.demir@gmail.com

Received: Feb 24, 2021

Accepted: Aug 22, 2021

${ }^{1}$ Krrkkkale Yüksek Ihtisas Hospital, Cardiology Krrkkale, Turkey

${ }^{2}$ Erzurum Regional Training and Research Hospital, Cardiology, Erzurum, Turkey

${ }^{3}$ Heart Center, Ataturk University Medical School, Cardiology, Erzurum, Turkey

${ }^{4}$ Hisar Intercontinental Hospital, Cardiology, Istanbul, Turkey

\section{Abstract}

Objectives: Although renal insufficiency is associated with high mortality in patients with acute coronary syndrome, studies have often excluded patients of advanced age who have renal insufficiency. The present study aimed to determine the relationship between renal insufficiency and mortality predictors in patients with non-ST-segment elevation myocardial infarction (NSTEMI) who were aged 65 and older.

Methods: The study included 537 NSTEMI patients aged 65 years and over, who were followed up for at least 12 months, who were admitted to the hospital with the diagnosis of NSTEMI and underwent coronary angiography. Sociodemographic and clinical features, laboratory parameters, and clinical evaluation variables were recorded at the time of admission. The patients were divided into four groups according to their ages and creatinine clearance values.

Results: The mean age of the patients was $76.17 \pm 6.64$ years, and 256 (47.7\%) of them were women. According to the applied multivariate age-stratified Cox regression analysis, independent predictors of one-year mortality were found to be creatinine clearance $(p=0.005)$, left ventricular ejection fraction $(p<0.001)$, and coronary revascularization $(p=0.004)$.

Conclusion: Creatinine clearance, left ventricular ejection fraction, and coronary revascularization are robust and independent predictors of one-year mortality in NSTEMI patients.

Keywords: Non-ST Elevated Myocardial Infarction; Renal Insufficiency; Mortality; Acute Coronary Syndrome. 


\section{INTRODUCTION}

Non-ST segment elevation myocardial infarction (NSTEMI) is one of the leading causes of mortality and morbidity in patients aged 65 years and old$\mathrm{er}$, and these numbers are increasing daily $(1,2)$. Although there is a decrease due to improvements in reperfusion technology and pharmacology, this patient group's mortality rate is heightened by their tendency toward ischemia and bleeding and increased frequency of comorbidities (3). Currently, the limited number of studies investigating mortality predictors in NSTEMI patients and the narrow inclusion criteria for patients in this research hinders the ability to generalize these studies' results to a patient population in clinical practice $(1,4,5)$.

Renal insufficiency (RI) is quite common in hospitalized patients with acute coronary syndrome (ACS) and affects $43 \%$ of patients diagnosed with NSTEMI (6). The prevalence of RI increases with age, and arrhythmia and cardiovascular diseases are the leading causes of death in these patients (7). Recent studies have shown that when compared to younger patients, NSTEMI patients who are older than 75 years of age have more significant absolute risk reduction in terms of mortality and morbidity when appropriate follow-up and treatment strategies are applied (8). Nonetheless, the number of studies investigating the validity of this condition is limited since elderly NSTEMI patients with RI are more vulnerable and the pharmacokinetic properties of the medications are varied $(9,10)$. While a significant number of studies dealing with this issue in Turkey show that RI may be a predictor for mortality (11-13), there are studies showing the opposite (14-16). However, very few of these studies seem to focus on geriatric patients $(11,17)$. For this reason, it would be useful to investigate the relationship between RI and mortality in this patient group that is likely to benefit from treatment. This study aimed to investigate the effect of RI on patients who had been hospitalized due to NSTEMI and were over the age of 65 in order to determine the predictors of mortality in a one-year follow-up.

\section{MATERIAL AND METHODS}

\section{Patient population}

The current study's sample consisted of patients aged 65 years or older who were admitted to the hospital and diagnosed with NSTEMI and were performed coronary angiography between 2016 and 2020. The study was planned as an observational report of routine clinical practice. In accordance with the inclusion and exclusion criteria, the study included patients who were undergoing coronary angiography and were treated according to the recommended guidelines and clinical approach. The patients' diagnoses and treatments were made in accordance with the current guidelines $(1,4)$. The study included patients who were older than 65 years of age and who had been diagnosed with NSTEMI and underwent coronary angiography. Patients younger than 65 years of age, who lacked troponin elevation or had proven troponin elevation due to other causes, and who had malignancies, primary arrhythmia, cardiogenic shock, cardiac arrest, a history of coronary bypass, or severe heart valve disease were excluded from the study. As a result, of the 593 patients who met the inclusion criteria, 56 were excluded, and a total of 537 patients with NSTEMI were included in the study. The approval for the study was obtained from the local ethics committee, and each stage of the study was carried out in accordance with the Helsinki Declaration.

\section{Study Design and Clinical Evaluation}

The study was designed as multicenter and prospective. Erzurum Regional Training and Research Hospital/Erzurum and Ministry of Health, 29 Mayıs State Hospital/Ankara participated in the study. Patients meeting the inclusion criteria were diagnosed with NSTEMI according to current guidelines, 
and coronary angiography was applied appropriately (1, 4). Patients who met the exclusion criteria or did not meet the inclusion criteria were excluded at this stage. The patients' sociodemographic characteristics, echocardiography and electrocardiography records, medical history, angiography images, and laboratory parameters were recorded. After the participants were treated according to the appropriate guidelines, they were followed up for at least 12 months (Mean \pm SD: 543.25 \pm 232.39 days, Median: 562 days). Patients were followed up by medical records or telephone. Patients for whom information could not be obtained were excluded from the study. The data recorded in the dataset were statistically analyzed.

The centers participating in the study met the quality assessment criteria for the accuracy of laboratory measurements and follow-up of clinical laboratory measurement results. Routine biochemical and hematological tests of the participants were performed during their hospitalizations. Echocardiographic examinations of the patients were performed using the Vivid 7 (General Electric-Vingmed, Milwaukee, WI, USA) device, and left ventriculary ejection fraction (LVEF) measurements were made according to the modified Simpson's method. During follow-up of the patients, GRACE risk calculations were performed by the clinician who performed the follow-up. The coronary angiography images of the patients were examined, and SYNTAX and Gensini scores were calculated by two experienced cardiology specialists. The patients who were treated by coronary bypass or percutaneous methods after coronary angiography were defined as patients who underwent coronary revascularization. Creatinine clearance $(\mathrm{CrCl})$ levels were calculated using the Cockroft-Gault equation. For the purposes of this study, patients were divided into four categories: those who were 65-74 years of age and had $\mathrm{CrCl}$ levels of $\geq 60 \mathrm{ml} / \mathrm{min}$; those who were $65-74$ years of age and had $\mathrm{CrCl}$ levels of $<60 \mathrm{ml} /$ $\mathrm{min}$; those who were $\geq 75$ years of age and had $\mathrm{CrCl}$ levels of $\geq 60 \mathrm{ml} / \mathrm{min}$; and those who were $\geq$ 75 years of age and had $\mathrm{CrCl}$ levels of $<60 \mathrm{ml} / \mathrm{min}$.
Follow-up controls were planned at the end of one month and one year. In cases of insufficient data, national or hospital records were used.

\section{Statistical Analyses}

The descriptive analyses were presented as numbers and percentages for categorical variables and as means and standard deviations for continuous variables. The Pearson Chi-square test was used to evaluate the categorical data from the group comparison. After the assessment of the parametric assumptions in the comparison of continuous variables, one-way ANOVA and Tukey tests were used in post-hoc analysis. Kaplan-Meier plots were used to compare survival rates between the four groups. Then, in order to show the differences in hazard between the age groups, a stratified Cox regression model approach was used. Hazard ratios (HR) and associated 95\% Confidential Intervals (Cl) were presented to show the differences in mortality risk between the age groups. Special relationships between the potential predictors and survival were tested by using a univariate stratified Cox regression. Variables that were statistically significant in univariate analyses were included in the multivariate models. Only existing variables were considered to be potential predictors. "Survival probability" was calculated for each patient, and its relationship with mortality predictors was examined by using the stratified Cox regression model. Statistical analyses of the data were performed using SPSS version 22 software (SPSS, Inc., Chicago, IL). A value of $\mathrm{p} \leq 0.05$ was considered statistically significant.

\section{RESULTS}

The mean age of the patients was $76.17 \pm 6.64$ years. At least 281 (52.3\%) of the participants were male and 256 (47.7\%) were female. In 101 (43.5\%) of the 232 (43.2\%) patients aged 65-74, $\mathrm{CrCl}$ levels were $<60 \mathrm{ml} / \mathrm{min}$, and in 131 (56.5\%) patients, $\mathrm{CrCl}$ levels were $\geq 60 \mathrm{ml} / \mathrm{min}$. By comparison, in 256 
(83.9\%) of the 305 (56.8\%) patients aged 75 years and older, $\mathrm{CrCl}$ levels were $<60 \mathrm{ml} / \mathrm{min}$, and in 49 (16.1\%) patients, $\mathrm{CrCl}$ levels were $\geq 60 \mathrm{ml} / \mathrm{min}$. Table 1 presents the comparison of the clinical features of the participants in the four study groups. Accordingly, we found statistical differences between the groups in terms of age $(p<0.001)$, gender $(p<$ $0.001)$, smoking $(p=0.001)$, diabetes mellitus $(p=$ $0.001)$, hypertension $(p<0.001)$, atrial fibrillation ( $p$ $<0.001)$, coronary artery disease $(p<0.001)$, percutaneous coronary intervention history $(p<0.001)$, and stroke history $(p<0.001)$. Statistical differences between the four groups were also found in ST-segment deviation ( $p=0.034$ ), coronary revascularization ( $p=0.014)$, LVEF $(p=0.028)$, and GRACE scores $(p<0.001)$. After patients were discharged, statistically significant differences were found between the groups' use of warfarin $(p<0.001)$, new oral anticoagulant $(p<0.001)$, renin-angiotensin system blockers ( $p=0.031)$, Beta-blockers $(p=0.008)$, and statin ( $p=0.002$ ). In addition, we found statistically significant differences between all causes of mortality, one-month follow-up $(p=0.016)$, and one-year follow-up $(p<0.001)$.

Mortality predictors for elderly NSTEMI patients were examined using the age-stratified Cox regression model (Table 2). In the univariate model, the differences between ST-segment deviation (HR: 1.973, 95\% Cl: 0.1.349-3.428, $p=0.004)$, coronary revascularization (HR: $0.492,95 \% \mathrm{Cl}: 0.308-0.786$, $\mathrm{p}=0.003), \mathrm{CrCl}$ (HR: $0.963,95 \% \mathrm{Cl}: 0.948-0.977, \mathrm{p}$ $<0.001$ ), LVEF (HR: $0.921,95 \%$ Cl: 0.900-0.943, p < 0.001), hemoglobin (HR: $0.841,95 \% \mathrm{Cl}: 0.740-0.956$, $\mathrm{p}=0.008$ ), and SYNTAX scores (HR: $1.029,95 \% \mathrm{Cl}$ : 1.007-1.052, $p=0.010$ ) were found to be statistically significant. In the multivariate stratified Cox regression model, the differences between coronary revascularization (HR: $0.447,95 \% \mathrm{Cl}$ : 0.258-0.776, $\mathrm{p}$ $=0.004), \mathrm{CrCl}$ (HR: $0.973,95 \% \mathrm{Cl}: 0.954-0.991, \mathrm{p}=$ 0.005), and LVEF (HR: 0.944, 95\% Cl: 0.919-0.970, p $<0.001)$ were statistically significant (-2 Log Likelihood: 578.438). Figure 1 and Figure 2 present the relationships between each patient's survival probability (calculated by multivariate stratified Cox regression analysis) and age, diabetes mellitus, gender, $\mathrm{CrCl}$, hemoglobin, LVEF, coronary revascularization, ST-segment deviation, and SYNTAX scores. Figure 3 shows the one-year survival probability curves according to the creatinine clearance (Adjusted to: age, gender, ST segment deviation, revascularization, LVEF, hemoglobin, diabetes mellitus and SYNTAX).

\section{DISCUSSION}

The most prominent finding from the current study, which examined the relationship between renal failure and one-year mortality rates for all causes in NSTEMI patients aged 65 years and older, was that $\mathrm{CrCl}, \mathrm{LVEF}$, and coronary revascularization are independent predictors of one-year mortality, regardless of age. We believe that the results of our study are important since they may be instructive for predicting mortality in patients with NSTEMI aged 65 and over.

A number of atherosclerotic processes are activated due to the disruption of vascular elasticity, changes in coagulation and hemostasis mechanisms, endothelial dysfunction, and changes in regeneration capacity with aging or the addition of comorbidities. Moreover, an increasing majority of patients with ACS consist of patients aged 65 and older (18). These individuals are at a high risk of experiencing ischemic events and bleeding due to their higher rates of comorbidities. Although treatment guidelines recommend that elderly patients should be approached in a similar way to that of young patients, there are limited data regarding risk and treatment management for these patient groups since they are excluded in most randomized trials $(5,19)$. In elderly patients, admission to the hospital and diagnosis are delayed due to atypical symptoms, and interventional or strong antiaggregant treatments are performed less than in 
Table 1. Baseline characteristics of study subjects according to age and $\mathrm{CrCl}$.

\begin{tabular}{|c|c|c|c|c|c|}
\hline \multirow{2}{*}{\begin{tabular}{|l} 
Variable \\
$\mathrm{CrCl}$ Groups
\end{tabular}} & \multicolumn{2}{|c|}{ Patients aged $65-74$ years $(n=232)$} & \multicolumn{2}{|c|}{ Patients aged $\geq 75$ years $(n=305)$} & \multirow[t]{2}{*}{ P-Value } \\
\hline & $\begin{array}{l}\mathrm{CrCl}<60 \\
(n=101)\end{array}$ & $\begin{array}{l}\mathrm{CrCl} \geq 60 \\
(\mathrm{n}=131)\end{array}$ & $\begin{array}{l}\mathrm{CrCl}<60 \\
(n=256)\end{array}$ & $\begin{array}{c}\mathrm{CrCl} \geq 60 \\
(n=49)\end{array}$ & \\
\hline Age (years) (Mean $\pm S D)$ & $70.94 \pm 2.53$ & $69.48 \pm 2.71^{*}$ & $81.29 \pm 4.88^{* \#}$ & $78.10 \pm 3.02^{* \# £}$ & $<0.001$ \\
\hline Gender (female) & $47(46.5 \%)$ & $35(26.7 \%)^{*}$ & $157(61.3 \%)^{* \#}$ & $17(34.7 \%)^{£}$ & $<0.001$ \\
\hline Current Smoke & $15(14.9 \%)$ & $31(23.7 \%)$ & $24(10.5 \%)^{\#}$ & $4(8.2 \%)^{\#}$ & 0.001 \\
\hline Diabetes Mellitus & $43(42.6 \%)$ & $29(22.1 \%)^{*}$ & $90(35.2 \%)^{\#}$ & $9(18.4 \%)^{* f}$ & 0.001 \\
\hline Hypertension & $86(85.1 \%)$ & $73(55.7 \%)^{\star}$ & $187(73.0 \%)^{* \#}$ & $35(71.4 \%)^{*}$ & $<0.001$ \\
\hline Atrial Fibrillation & 20 (19.8\%) & $7(5.3 \%)^{*}$ & $76(29.7 \%)^{\#}$ & $8(16.3 \%)^{\#}$ & $<0.001$ \\
\hline Prior CAD & $60(59.4 \%)$ & $30(22.9 \%)^{*}$ & $118(46.1 \%)^{\star \#}$ & $21(42.9 \%)^{\#}$ & $<0.001$ \\
\hline Prior $\mathrm{PCl}$ & $40(39.6 \%)$ & $4(3.1 \%)^{*}$ & $52(20.3 \%)^{* \#}$ & $8(16.3 \%)^{* \#}$ & $<0.001$ \\
\hline Prior Stroke & $0(0)$ & $1(0.8 \%)$ & $21(8.2 \%)^{* \#}$ & $0(0)^{f}$ & $<0.001$ \\
\hline ST segment deviation & $28(27.7 \%)$ & $29(22.1 \%)$ & $13(26.5 \%)^{\#}$ & $92(35.9 \%)$ & 0.034 \\
\hline Coronary Revascularization & 75 (74.6\%) & 99 (75.6\%) & $157(61.3 \%)^{* \#}$ & 32 (65.3\%) & 0.014 \\
\hline LVEF (\%) (mean \pm SD) & $49.23 \pm 10.29$ & $51.14 \pm 8.56$ & $50.18 \pm 9.67$ & $53.91 \pm 8.20^{*}$ & 0.028 \\
\hline SYNTAX Score (mean \pm SD) & $10.36 \pm 8.77$ & $11.58 \pm 8.59$ & $11.57 \pm 11.27$ & $11.24 \pm 9.73$ & 0.802 \\
\hline Grace Score (mean \pm SD) & $130.08 \pm 17.61$ & $120.36 \pm 13.30^{*}$ & $147.31 \pm 22.79^{* \#}$ & $129.09 \pm 17.75^{f}$ & $<0.001$ \\
\hline Gensini Score (mean \pm SD) & $27.07 \pm 18.21$ & $30.22 \pm 17.72$ & $32.11 \pm 25.88$ & $23.87 \pm 18.27$ & 0.123 \\
\hline Hemoglobin (mean \pm SD) & $12.30 \pm 2.02$ & $13.73 \pm 2.09^{*}$ & $12.24 \pm 1.65^{\#}$ & $14.07 \pm 1.49^{*} \mathrm{f}$ & $<0.001$ \\
\hline Creatinine (mean $\pm \mathrm{SD})$ & $1.77 \pm 1.25$ & $0.98 \pm 0.19^{*}$ & $1.38 \pm 0.68^{\star \#}$ & $0.96 \pm 0.18^{*} f$ & $<0.001$ \\
\hline Creatinine clearance (mean \pm SD) & $44.43 \pm 12.66$ & $77.91 \pm 13.56^{*}$ & $44.09 \pm 10.77^{\#}$ & $68.16 \pm 6.82^{* \# f}$ & $<0.001$ \\
\hline \multicolumn{6}{|l|}{ Discharge Medications } \\
\hline Acetyl Salicylic Aside & 81 (80.2\%) & $119(90.8 \%)$ & 211 (82.4\%) & $41(83.7 \%)$ & 0.104 \\
\hline Clopidogrel & $81(80.2 \%)$ & 104 (79.4\%) & 205 (80.1\%) & $36(73.5 \%)$ & 0.763 \\
\hline Warfarin & $24(23.8 \%)$ & $10(7.6 \%)^{*}$ & $24(9.4 \%)^{*}$ & $2(4.1 \%)^{*}$ & $<0.001$ \\
\hline New oral anticoagulant & $4(4.3 \%)$ & 0 & $44(190 \%)^{* \#}$ & $8(24.2 \%)^{* \#}$ & $<0.001$ \\
\hline RAS blockers & $63(62.4 \%)$ & $82(62.6 \%)$ & $186(72.7 \%)^{\#}$ & $27(55.1 \%)^{£}$ & 0.031 \\
\hline Beta-Blockers & $84(83.2 \%)$ & $115(87.8 \%)$ & $238(93.0 \%)^{*}$ & $39(79.6 \%)^{f}$ & 0.008 \\
\hline Statin & 57 (56.4\%) & $104(79.4 \%)^{\star}$ & $165(64.5 \%)^{\#}$ & $33(67.3 \%)$ & 0.002 \\
\hline Hospitalization days (mean \pm SD) & $6.78 \pm 6.90$ & $6.54 \pm 7.38$ & $6.94 \pm 5.58$ & $4.95 \pm 3.40$ & 0.229 \\
\hline One-month mortality & $8(7.9 \%)$ & $1(0.8 \%)^{*}$ & $11(4.3 \%)$ & $0(0)^{*}$ & 0.016 \\
\hline One-year mortality & 9 (8.9\%) & 7 (5.3\%) & $49(19.1 \%)^{* \#}$ & $6(12.2 \%)$ & $<0.001$ \\
\hline
\end{tabular}

$\mathrm{CrCl}$ : Creatinine clearance (ml/min.); SD: Standard deviation; CAD: Coronary Artery Disease; LVEF: Left ventricular ejection fraction; $\mathrm{PCl}$ : Percutaneous Coronary Intervention; RAS: Renin-angiotensin aldosterone system. The $\mathrm{p}$-value indicates the statistical difference between the four groups.

${ }^{*} \mathrm{P}<0.05$, vs. Patients aged $65-74$ years and $\mathrm{CrCl}<60$

$\# P<0.05$, vs. Patients aged $65-74$ years and $\mathrm{CrCl} \geq 60$

${ }^{\mathrm{f}} \mathrm{P}<0.05$, vs. Patients aged $\geq 75$ years and $\mathrm{CrCl}<60$ 
Table 2. Predictors of one-year mortality: Univariable and multivariable age-stratified Cox regression analysis

\begin{tabular}{|c|c|c|c|c|}
\hline \multirow[b]{2}{*}{ Predictor } & \multicolumn{2}{|c|}{ Univariable } & \multicolumn{2}{|c|}{ Multivariable } \\
\hline & $\begin{array}{l}\text { Hazard Ratio } \\
\qquad(95 \% \mathrm{Cl})\end{array}$ & P-Value & $\begin{array}{l}\text { Hazard Ratio } \\
\qquad(95 \% \mathrm{Cl})\end{array}$ & P-Value \\
\hline \multicolumn{5}{|l|}{ All Patients } \\
\hline ST segment deviation & $\begin{array}{c}1.973 \\
(1.349-3.428)\end{array}$ & 0.004 & $\begin{array}{c}1.518 \\
(0.853-2.702)\end{array}$ & 0.156 \\
\hline Revascularization & $\begin{array}{c}0.492 \\
(0.308-0.786)\end{array}$ & 0.003 & $\begin{array}{c}0.447 \\
(0.258-0.776)\end{array}$ & 0.004 \\
\hline $\mathrm{CrCl}(\mathrm{ml} / \mathrm{min}$.) (one-point increase) & $\begin{array}{c}0.963 \\
(0.948-0.977)\end{array}$ & $<0.001$ & $\begin{array}{c}0.973 \\
(0.954-0.991)\end{array}$ & 0.005 \\
\hline LVEF (\%) (one-point increase) & $\begin{array}{c}0.921 \\
(0.900-0.943)\end{array}$ & $<0.001$ & $\begin{array}{c}0.944 \\
(0.919-0.970)\end{array}$ & $<0.001$ \\
\hline Hemoglobin (mg/dl) (one-point increase) & $\begin{array}{c}0.841 \\
(0.740-0.956)\end{array}$ & 0.008 & $\begin{array}{c}1.094 \\
(0.943-1.269)\end{array}$ & 0.234 \\
\hline Diabetes Mellitus & $\begin{array}{c}1.343 \\
(0.832-2.169) \\
\end{array}$ & 0.228 & & \\
\hline SYNTAX Score (one-point increase) & $\begin{array}{c}1.029 \\
(1.007-1.052)\end{array}$ & 0.010 & $\begin{array}{c}1.022 \\
(0.999-1.046)\end{array}$ & 0.064 \\
\hline
\end{tabular}

$\mathrm{CrCl}$ : Creatinine clearance (ml/min.); LVEF: Left ventricular ejection fraction.

younger populations due to increased risk of bleeding and comorbidities. Therefore, elderly patients face a higher risk of mortality $(9,19,20)$. As in other studies in the literature, age was shown to be associated with mortality in the present study $(5,11)$.

One of the most important and common comorbidities affecting mortality in ACS patients is RI (21, 22). Although coronary artery disease and post-ACS mortality are more common in patients with endstage renal failure or dialysis, several studies have indicated that mortality rates are also high in patients with mild-to-moderate chronic kidney disease (22). In a study examining the length of hospital stays in NSTEMI patients, RI was associated with prolonged hospital stays, transfers to the catheter lab were delayed, and fewer of the recommended treatments were applied (5). In another study investigating the causes of mortality in NSTEMI patients aged 75 years and older, mortality was found to be associated with $\mathrm{CrCl}$, hemoglobin levels, age, and LVEF (23). In an ACUITY study that investigated the one-year mortality of 2627 patients, anatomical SYNTAX scores, $\mathrm{CrCl}$, age, and LVEF were found to be indicators of mortality and were included in the Core model, which was recommended as a new scoring system (24).

In the present study, $\mathrm{CrCl}$ has been shown to be a predictor of mortality in ACS patients, similar to a significant portion of the literature $(11,12,21)$. However, there are limited number of studies conducted with geriatric patients in our country (17). Likewise, few of the studies focus on NSTEMI patients $(11,12)$. Considering that geriatric NSTEMI patients may benefit relatively more from appropriate follow-up and treatment, the results of present study gain importance (23). However, it should be 
Figure 1. Relative Hazard plots for the effects of predictors on mortality.
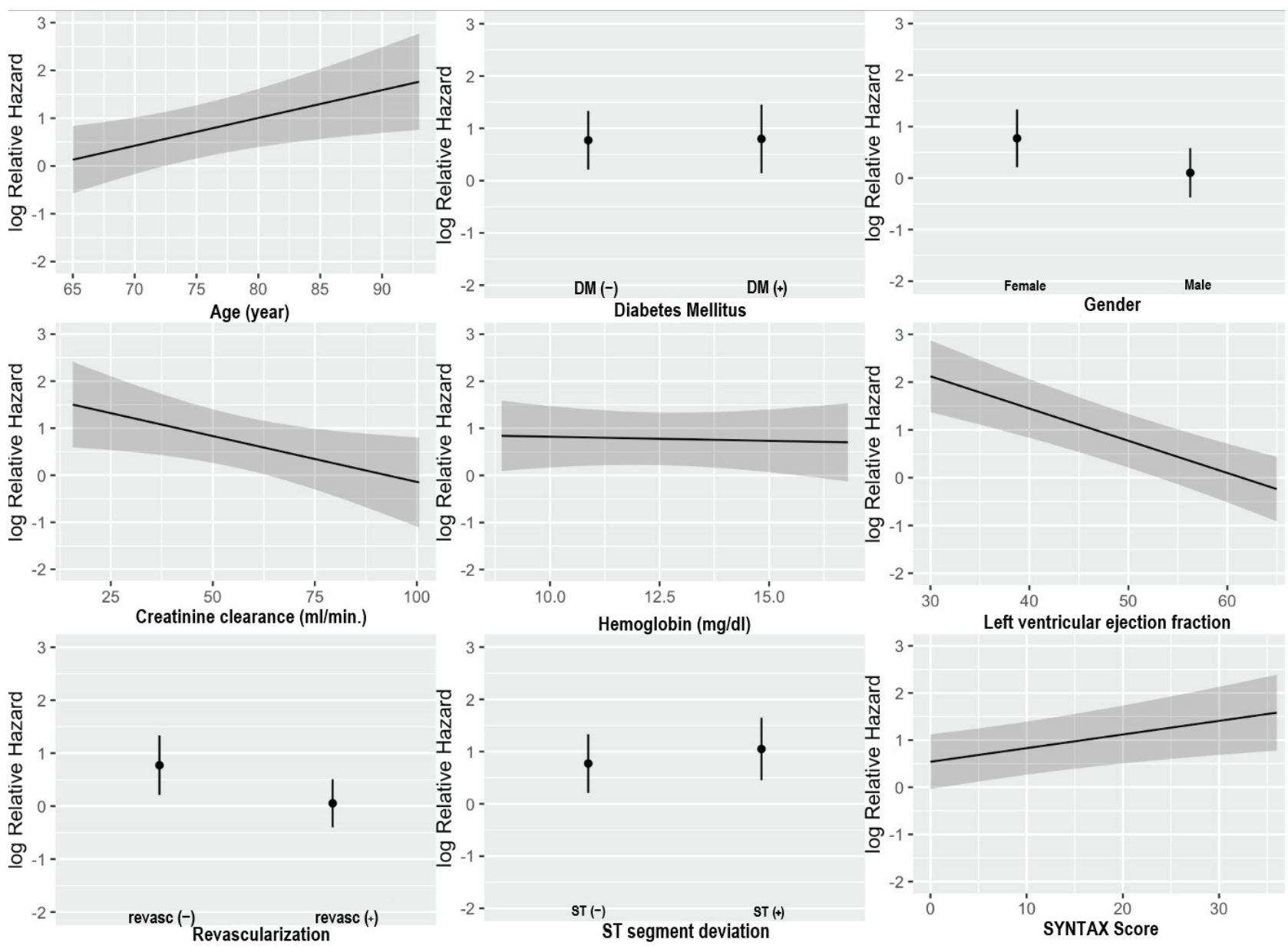

considered that the results of present study will be useful in clarifying the relationship between $\mathrm{CrCl}$ and mortality, since there are few studies conducted in Turkey on this patient group and some of these studies did not find a relationship between $\mathrm{CrCl}$ and mortality. Various factors may describe the relationship between mortality and RI in patients with geriatric NSTEMI. The most probable causes of this condition can include increased frequency of heart disease due to oxidative stress, vascular endothelial dysfunction, acceleration of cellular apoptosis, and the contribution of various immune system disorders, in addition to factors related to atherosclerosis in RI patients, which may include lipid disorders, hypertension, concomitant diabetes mellitus, or chronic inflammation processes (25). These patients may also experience higher rates of mortality due to the decreased frequency in which they undergo coronary revascularization or treatments involving antiaggregants, beta-blockers, RAS blockers, and statins, which are administered less often to patients with RI during hospitalization and after discharge (26). In our study, the rates of usage RAS blockers, beta-blockers in discharge are 
Figure 2. Graphical representation of the relationship between survival probability and creatinine clearance according to the age.

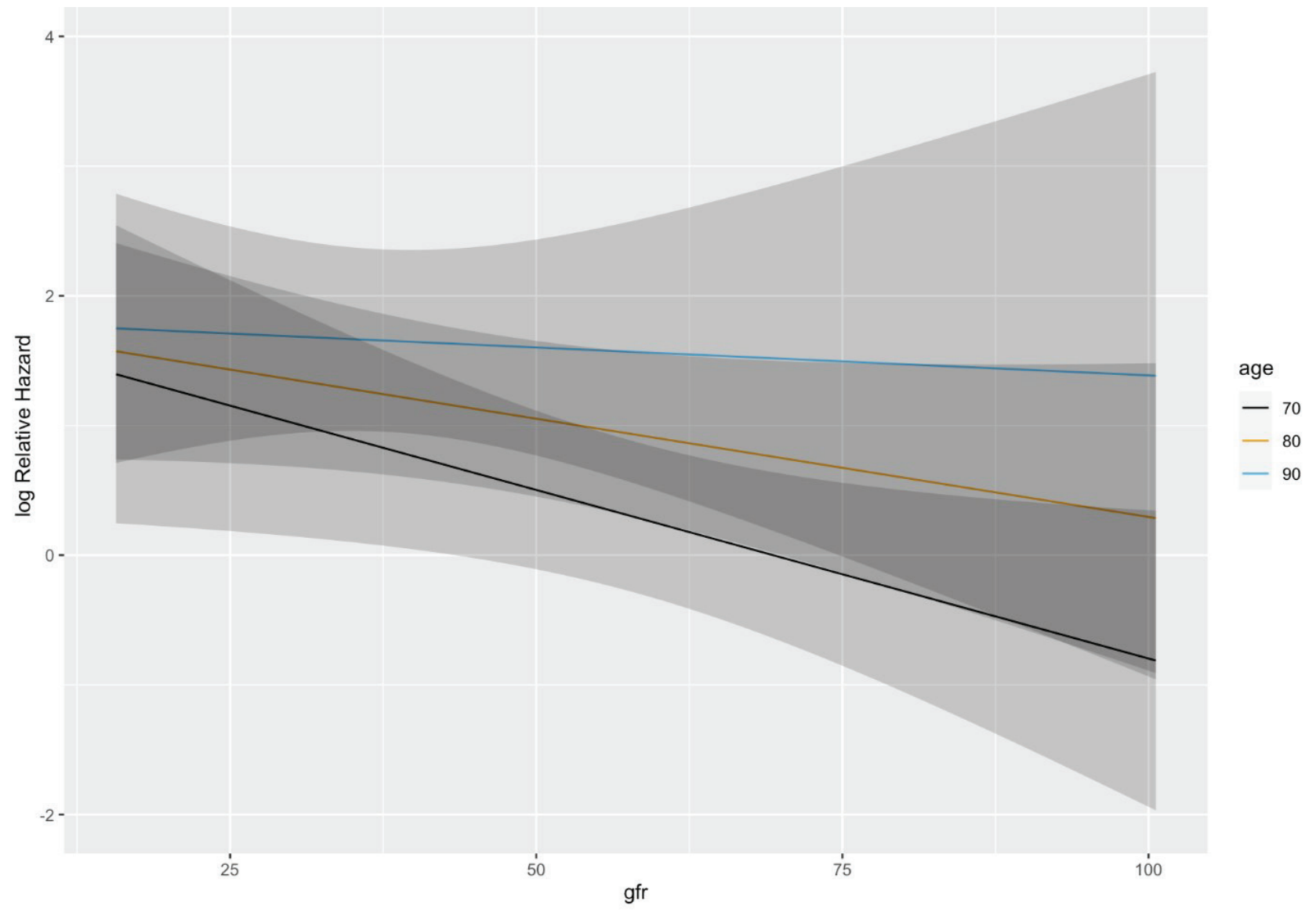

lower in older than 75 years with RI than the other patients' groups. This may be a reason for the difference in mortality between patient groups. However, this statement may not apply to statins because the beneficial effects of statin therapy appear after at least one year of treatment (27).

According to guidelines, it is recommended that elderly NSTEMI patients receive individualized therapy and adhere to the same treatment strategies as younger patients $(1,4)$. In the literature, revascularization has been shown to decrease mortality and morbidity in elderly NSTEMI patients $(5,23)$. However, in clinical practice, clinicians opt for less invasive therapies since they consider advanced age to act as an obstacle to invasive intervention $(11,23,28)$. Advanced age can also lead to delays in invasive intervention and to increases in undesired results (5). Similar to the findings from the literature, the results of the current study indicated that coronary revascularization is associated with reductions in one-year mortality. These results indicate that, unlike clinical practice, invasive intervention is effective in reducing mortality and morbidity regardless of age.

Although predictors of mortality in NSTEMI patients have been demonstrated in previous studies, 
Figure 3. The survival probability in patients according to the creatinine clearance.

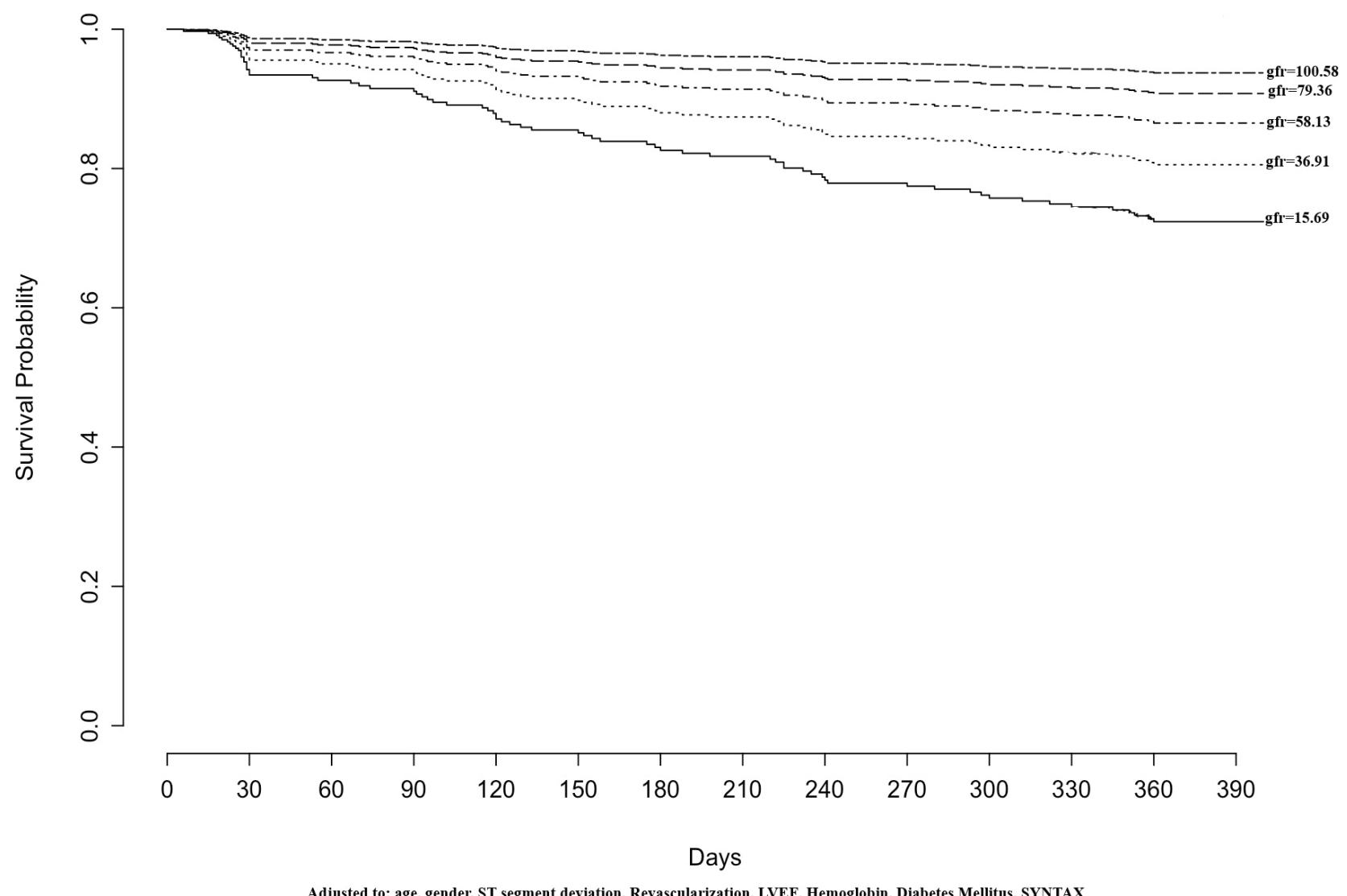

patients aged 75 years and older and patients with additional comorbidities such as chronic renal failure were excluded from randomized controlled trials until the last few years. In spite of the fact that is recommended to receive similar treatments with other patients in this risky patient group among current treatment recommendations, both invasive and non-invasive treatment applications are insufficient in real life. Because these patients have many comorbidities, multidrug using and some metabolic changes so the clinicians are far from applying the same treatment as younger patients (29). Our study draws attention to a group of patients with high mortality and may be a warning to be more devoted in providing follow-up and treatment optimization in these patients.

Many studies have shown LVEF to be a consistent predictor of short- and long-term mortality in patients with ACS $(30,31)$. In addition, recommendations have been made to include LVEF in risk scoring systems, such as GRACE (32). In the present study, LVEF was found to be an important independent predictor of one-year mortality in elderly NSTEMI patients. Therefore, we recommend using the LVEF assessment, which is a parameter of echocardiographic measurement, as an easily accessible 
and noninvasive method during the follow-up and risk assessment of patients.

\section{Limitations}

Our study has some important limitations. First, the follow-up period of our study was brief, and it presented all causes of mortality. It would be more beneficial to present cardiac-related mortality, specifically. It is also worth noting that neglecting the factors that can affect mortality, such as possible complications due to invasive treatment, may have affected the results. In addition, clinicians may have taken different approaches in treating the patients. The study was also limited by discrepancies between how clinics applied LVEF measurements and because some clinics did not discharge LVEF measurements.

\section{CONCLUSION}

Elderly NSTEMI patients with RI are at high risk for mortality, and the administration of guideline-based therapies is controversial. $\mathrm{CrCl}$, coronary revascularization, and LVEF are potent and independent predictors of one-year mortality of all causes. Our results support the available information in the literature and provide new insights into the risk assessment of this complex patient population. Considering these predictors together can prove useful during early risk assessments. In addition, careful application of guidelines for elderly NSTEMI patients with Rl should be considered effective in reducing mortality. Future studies should focus on optimizing more aggressive treatments to manage mortality in this patient group.

Conflict of interest: None declared.

Funding: The authors received no financial support for the research, authorship, and/or publication of this article.

the European Society of Cardiology (ESC). Eur Heart J. 2016; 37(3): 267-315. (PMID: 26320110)

5. Vavalle JP, Lopes RD, Chen AY, et al. Hospital length of stay in patients with non-ST-segment elevation myocardial infarction. Am J Med 2012;125(11):108594. (PMID: 22921886)

6. Baber U, Auguste U. Patients with chronic kidney disease/diabetes mellitus: the high-risk profile in acute coronary syndrome. Curr Cardiol Rep 2013;15(8):386. (PMID: 23843182)

7. Anavekar NS, McMurray JJ, Velazquez EJ, et al. Relation between renal dysfunction and cardiovascular outcomes after myocardial infarction. N Engl J Med 2004;351 (13):1285-95. (PMID: 15385655)

8. Morici N, De Servi S, Toso A, et al. Renal dysfunction, coronary revascularization and mortality among elderly patients with non ST elevation acute coronary syndrome. Eur Heart J Acute Cardiovasc Care 2015;4(5):453-60. (PMID: 25348274)

9. Gimbel M, Ten Berg J. Management of elderly patients with a non-ST-segment-elevation acute coronary syndrome. Neth Heart J 2017;25(7-8):409-15. (PMID: 28516369) 
10. Llaó I, Formiga F, Solé AA, et al. Frequency of Renal Dysfunction and Frailty in Patients $\geq 80$ Years of Age With Acute Coronary Syndromes. Am J Cardiol 2019;123(5):729-35. (PMID: 30593340)

11. Gündoğmuş PD, Ölçü EB, Öz A, et al. The Effects of Percutaneous Coronary Intervention on Mortality in Elderly Patients with Non-ST-Segment Elevation Myocardial Infarction Undergoing Coronary Angiography. Scott Med J 2020;65 (3):81-8. (PMID: 32772677)

12. Guclu K, Celik M. Prognostic Value of Inflammation Parameters in Patients With Non-ST Elevation Acute Coronary Syndromes. Angiology. 2020;71:825-30. (PMID: 32597198)

13. Kalyoncuoğlu M, Katkat F, Biter HI, Cakal S, Tosu AR, Can MM. Predicting One-Year Deaths and Major Adverse Vascular Events with the Controlling Nutritional Status Score in Elderly Patients with Non-ST-Elevated Myocardial Infarction Undergoing Percutaneous Coronary Intervention. J Clin Med. 2021;10:2247. (PMID: 34067233)

14. Kırış T, Yazici S, Günaydin ZY, Akyüz Ş, Güzelburç Ö, Atmaca H, Ertürk M, Nazli C, Dogan A. The Prognostic Impact of In-Hospital Change in Mean Platelet Volume in Patients With Non-ST-Segment Elevation Myocardial Infarction. Angiology. 2016;67:690-6. (PMID: 26787684)

15. Yazıcı S, Kırış T, Ceylan US, Terzi S, Erdem A, Atasoy I, Emre A, Yeşilçimen K. Relation of Low T3 to One? Year Mortality in Non-ST?Elevation Acute Coronary Syndrome Patients. J Clin Lab Anal. 2017;31:e22036. (PMID: 27566539)

16. Alici G, Quisi A, Omer G, Harbalioğlu H, Allahverdiyev S, Yildirim A, Urgun ÖD, Mustafa G. Mortality Outcomes of Single-staged versus Multi-staged Complete Coronary Revascularization in Multivessel Non-ST Elevation Myocardial Infarction Patients. Duzce Med J. 2021. (DOI:https://doi.org/10.18678/ dtfd.868952)

17. Atas H, Tigen K, Ozben B, Kartal F, Gurel E, Atas DB, Sari I, Basaran Y. Short and Long Term Mortality Predictors in Octogenarians with Acute Coronary Syndromes. Clin Invest Med. 2018:E43-E50. (PMID: 29959882)

18. Badimon L, Bugiardini R, Cubedo J. Pathophysiology of acute coronary syndromes in the elderly.Int J Cardiol 2016;222:1105-9. (PMID: 27499220)

19. Lattuca B, Kerneis M, Zeitouni M, et al. Elderly Pa- tients with ST-Segment Elevation Myocardial Infarction: A Patient-Centered Approach. Drugs Aging 2019;36(6):531-9. (PMID: 30953328)

20. Zaman MJ, Stirling S, Shepstone L, et al. The association between older age and receipt of care and outcomes in patients with acute coronary syndromes: a cohort study of the Myocardial Ischaemia National Audit Project (MINAP). Eur Heart J 2014;35(23):15518. (PMID: 24644310)

21. Morici N, De Servi S, Toso A, et al. Renal function estimation and one-year mortality in elderly patients with non-ST-segment elevation acute coronary syndromes. Int J Cardiol 2014;174 (1):127-8. (PMID: 24447752)

22. Asim M, Jeffrey RF. Management of acute coronary syndrome in patients with chronic kidney disease: if we don't risk anything, we risk even more. Nephron Clin Pract 2011;119 (4):c333-c7. (PMID: 22135792)

23. Morici N, Savonitto S, Murena E, Antonicelli R, Piovaccari G, Tucci D, Tamburino C, Fontanelli A, Bolognese L, Menozzi M. Causes of death in patients $\geq 75$ years of age with non-ST-segment elevation acute coronary syndrome. The American journal of cardiology. 2013;112:1-7.

24. Farooq $V$, Vergouwe $Y$, Généreux $P$, et al. Prediction of 1-year mortality in patients with acute coronary syndromes undergoing percutaneous coronary intervention: validation of the logistic clinical SYNTAX (Synergy Between Percutaneous Coronary Interventions With Taxus and Cardiac Surgery) score. JACC Cardiovasc Interv 2013;6 (7):737-45. (PMID: 23866185)

25. Jagieła J, Bartnicki P, Rysz J. Selected cardiovascular risk factors in early stages of chronic kidney disease. Int Urol Nephrol 2020;52:303-14. (PMID: 31955363)

26. Patti G, Ricottini E, Nenna A, et al. Impact of chronic renal failure on ischemic and bleeding events at 1 year in patients with acute coronary syndrome (from the Multicenter START ANTIPLATELET Registry). American J Cardiol 2018;122 (6):936-43. (PMID: 30057232)

27. Horodinschi R-N, Stanescu AMA, Bratu OG, et al. Treatment with statins in elderly patients. Medicina. 2019;55:721. (PMID: 15100205).

28. Llaó I, Ariza-Sole A, Sanchis J, et al. Invasive strategy and frailty in very elderly patients with acute coronary syndromes. Eurolntervention 2018;14(3):e336-e42. (PMID: 29616624) 
29. Usta C, Bedel A. Update on pharmacological treatment of acute coronary syndrome without persistent ST segment elevation myocardial infarction in the elderly. J Geriatr Cardiol 2017;14:457-64. (PMID: 28868074)

30. Brezinov OP, Klempfner R, Zekry SB, et al. Prognostic value of ejection fraction in patients admitted with acute coronary syndrome: a real world study. Medicine (Baltimore) 2017;96 (9:e6226). (PMID: 28248882)
31. Siontis GC, Branca M, Serruys $P$, et al. Impact of left ventricular function on clinical outcomes among patients with coronary artery disease. Eur J Prev Cardiol 2019;26 (12):1273-84. (PMID: 30966820)

32. Li Y-m, Li Z-I, Chen F, et al. A LASSO-derived risk model for long-term mortality in Chinese patients with acute coronary syndrome.J Transl Med 2020;18(1):1-9. (PMID: 32252780) 